FACULdAdE de Formação de Professores

\title{
UMA ANÁLISE FUNCIONALISTA SOBRE O USO DOS SATÉLITES FONTE EM NOTÍCIAS “ON-LINE”
}

\author{
André William Alves de Assis (UEM) \\ assis.awa@gmail.com
}

\section{Introdução}

Quando um falante elege traços semânticos para uma proposição, seleciona entidades. Essa seleção de identidades é o que se conhece por estado-de-coisas, ou seja, uma codificação linguística que o falante faz da situação. Na linha de raciocínio de Dik (1989) e Pezzati (2005), pode-se dizer que a predicação (seleção) se divide em três níveis: predicação nuclear, estendida pelos operadores de predicado e satélites de nível 1; predicação estendida, uma predicação central estendida pelos operadores de predicação e satélites de nível 2 e a proposição, que é uma variável que simboliza um fato possível especificado pela predicação estendida, pelos operadores (que representam crença, esperança) e pelos satélites de nível 3 (que não mudam o estado-de-coisas, apenas restringem o valor que o falante dá ao conteúdo proposicional).

Este artigo traz como proposta de estudo a descrição destes satélites de nível 3, sob os pressupostos teóricos de Dik (1989), apresentados por Pezatti (2005), utilizados para especificar a origem, ou seja, a fonte de uma informação. Para investigarmos esses satélites, analisamos como corpus notícias veiculadas na internet, retiradas de portais e revistas reconhecidas nacionalmente, na pretensão geral de observar os usos mais frequentes dos satélites fonte no gênero notícia on line. Especificamente, pretendemos demonstrar como o uso desses satélites se processam, e como contribuem para a validade da proposição dentro do discurso, comprometendo ou não o falante com a verdade no cálculo pragmático do propósito discursivo. 


\section{Os níveis/camadas e os satélites}

Segundo Dik (1989), a estrutura subjacente da oração é uma estrutura abstrata complexa, hierarquicamente estruturada em camadas, são quatro os níveis apresentados por Pezatti $(2005)^{22}$, de uma perspectiva funcionalista". O nível mais baixo é forma o predicado e seus argumentos. Essa predicação nuclear, opcionalmente expandida por satélites de predicado (nível 1), constitui a 'predicação central', designação de um estado de coisas potencial; a predicação central pode, por sua vez, ser também expandida por satélites de predicação (nível 2), e assim formar a predicação estendida, uma entidade de segunda ordem referente a um Estado de coisas situado no espaço e no tempo concretos ou conceituais.

Essa estrutura é o input para a formação da proposição, de um fato possível, uma entidade de terceira ordem, que pode ser avaliada em termos de seu valor de verdade e, opcionalmente, ser expandida por satélites de nível mais alto (nível 3), tais como os atitudinais e os Fontes que especificam e validam o valor de verdade. Se um falante produz uma expressão, ele tem de selecionar uma força ilocucionária básica para essa proposição, formando assim uma entidade de 'quarta ordem' (nível 4). Cada tipo de entidade tem seu próprio tipo de operadores, meios não-lexicais para especificar informação adicional sobre o tipo de entidade envolvida.

Segundo Pezatti (2005), satélites são meios lexicais opcionais que veiculam informação adicional a uma das camadas no modelo hierárquico da oração. Esses satélites seriam opcionais porque a sua utilização ou a falta dela não afetam a estrutura da sentença, uma vez que a informação principal pertence a outra camada.

Observada a questão das camadas, as quais os satélites podem estar ligados, abordamos agora os quatro tipos de satélites existentes e sua unidade correspondente:

\footnotetext{
22 Este trabalho tem como referência o trabalho de Pezatti (2005) intitulado "A voz do outro, sob uma perspectiva funcionalista". Como são poucos os trabalhos sobre o tema e a própria autora disse que "a gramática tradicional é omissa" (p. 65), pois não fornece uma classificação que enquadre esses satélites fonte adequadamente, utilizamos este artigo como modelo para a estrutura de nosso trabalho. Pezatti baseia-se em textos de Dik "The theory of Funcitional Grammar" e ainda Dik, Hengeveld, Vester e Vet "The hierarchical structure of the clause and the typology of adverbial satellites".
} 


\section{FACULDADE dE FoRMAÇÃO de PROFESSORES}

\begin{tabular}{|cc|}
\hline Camada hospedeira & Tipos de satélites \\
\hline Predicado & satélites de predicado (nível 1) \\
\hline Predicação & satélites de predicação (nível 2) \\
\hline Proposição & Satélites de predicação (nível 3) \\
\hline Ilocução & Satélites de predicação (nível 4) \\
\hline
\end{tabular}

Figura 1. (Adaptado de Pezatti, 2005, p. 69)

Neste trabalho, interessa-nos os satélites de predicação (nível 3 ), por apresentarem o meio lexical pelo qual o falante especifica uma fonte, uma autoridade, para a validação da proposição.

\section{Os satélites de proposição}

Os satélites de proposição (nível 3) permitem ao falante avaliar o que ele apresenta como atos de fala, seja por meio dos satélites atitudinais, especificando sua atitude em relação a proposição, ou a parte dela ou então a validade da proposição; seja por meio dos satélites fonte, em que o falante se vale de uma estratégia de credibilidade de um outro, para estabelecer o nível de credibilidade ao texto.

Observamos aqui que esse tipo de satélite confere ao texto, o que Chaim Perelman ${ }^{23}$ chamou de "argumento por autoridade" (p. 347). Segundo ele, os argumentos seriam influenciados pelo prestígio e, uma mesma autoridade "pode ser valorizada ou desvalorizada conforme coincida ou não com a opinião dos oradores" (p. 350). Perelman não considerou a forma como esses argumentos eram introduzidos pelo falante, mas a abordagem argumentativa desses argumentos em muito nos interessa neste trabalho. A intenção do falante, o meio comunicativo e o gênero produzido em muito afetam a seleção das autoridades e, também, as escolhas dos constituintes que in-

\footnotetext{
${ }^{23}$ Chaim Perelman é um dos representantes de uma corrente filosófica e acadêmica que objetivava a recuperação da dignidade da retórica no século XX. Sua teoria encontra na argumentação o fundamento de uma nova racionalidade, isto é, passa a considerar a sua importância no pensamento e para o conhecimento. Seu livro Tratado da Argumentação inicia abordando elementos que poderiam ser classificados como pertencentes à esfera das estratégias. Perelman prima pelas exposições das escolhas a serem tomadas pelo orador, envolvendo os fatos e a seleção dos dados, as premissas relevantes, os valores a serem observados, os lugares, a matéria e a forma do discurso, as figuras de retórica e argumentação etc.
} 
serem as vozes que dão credibilidade ao texto; essa escolha é eminentemente argumentativa.

Num levantamento quantitativo inicial, observamos em nosso corpus 31 ocorrências de satélites fonte, que analisaremos segundo os aspectos de posição que ocupam na oração, os traços [+/-] humano e a intenção do falante. Vejamos os resultados completos no próximo tópico.

\section{Aspectos gramaticais}

Observamos nos textos analisados que existe uma preferência de satélites pelos falantes entre os 31 sintagmas nominais utilizados como satélites fonte. Nos textos analisados, evidenciamos uma maior utilização do satélite fonte "segundo" que perde seu valor tradicionalmente conformativo e funciona como um indicador de pessoa a quem se atribui uma opinião, são 14 ocorrências. "De acordo com", com 10 ocorrências é o segundo satélite mais utilizado. Em menor número temos o "para" com 4 ocorrências e o "conforme" com 3.

Nossos resultados são diferentes daqueles encontrados no texto de Pezatti. ${ }^{24}$ Observe a tabela 2:

\begin{tabular}{|ccc|}
\hline Satélites & Ocorrências & $\mathbf{\%}$ \\
\hline segundo & 14 & 45,16 \\
\hline de acordo com & 10 & 32,26 \\
\hline para & 4 & 12,90 \\
\hline conforme & 3 & 9,68 \\
\hline TOTAL & $\mathbf{3 1}$ & $\mathbf{1 0 0 \%}$ \\
\hline
\end{tabular}

Figura 2. Levantamento quantitativo dos satélites de nível 3 no corpus.

Em relação à ordem, observamos que em $78 \%$ dos casos, os satélites precedem o sujeito.

Segundo noticiou o Gulf News, Jobim declarou que espera que o acordo final seja apresentado em dois meses, antes da posse do novo governo brasileiro, em janeiro do ano que vem. O ministro brasileiro tam-

\footnotetext{
${ }^{24} \mathrm{Em}$ sua análise 0 "segundo" aparece como 0 mais utilizado, com 30 ocorrências. O "para" com 16 ocorrências" e o "de acordo com X" com 07, totalizando 53 ocorrências. Em nossa análise há uma inversão entre os dois últimos constituintes, e também apontamos o uso do "conforme".
} 


\section{FACULDADE de FoRMAÇÃO de PROFESSORES}

bém disse que o acordo era parte de uma iniciativa do Brasil de se tornar internacionalmente reconhecido na indústria militar, citou o diário. (Oestadao.com)

Para PGR, recurso de Roriz deve ser arquivado. O procurador-geral da República, Roberto Gurgel, encaminhou há pouco ao Supremo Tribunal Federal (STF) parecer em que pede que não tenha validade o julgamento do recurso do ex-candidato ao governo do DF Joaquim Roriz (PSC). (Oglobo.com)

Uma explicação para essa preferência pode ser explicada pelo princípio de ordenação icônica, que aponta para o fato de que a ordenação de constituintes pode ser explicada em termos de preferências, resultados de princípios funcionalmente motivados. Abordaremos este aspecto, para nós discursivos, no tópico 5 deste trabalho.

Interessante observar novamente que não há uma estrutura fixa, os satélites podem aparecer no começo, no meio ou no fim de uma proposição. A finalidade do emprego, a funcionalidade comunicativa é a que define o melhor posicionamento.

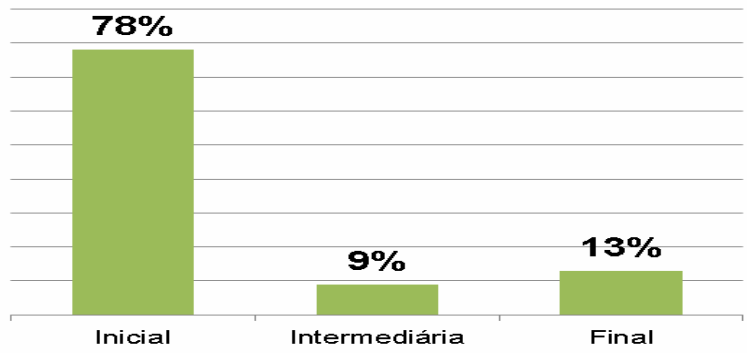

Figura 3. Resultado percentual de posicionamento dos satélites Fonte.

O que podemos observar em nossa análise é que as constituintes mais complexas são posicionadas preferencialmente no final das proposições, $13 \%$ as ocorrências. A colocação desse satélite em posição final parece ser motivada por ele funcionar como uma informação auxiliar na correta interpretação da oração:

O estado do Pará desmatou 220 quilômetros quadrados de floresta, o equivalente a 32 mil campos de futebol. As causas por trás desse título inglório de maior desmatador são velhas conhecidas da sociedade. "No Pará, há uma intensa expansão ilegal de áreas de pastagem para pecuária e de agronegócios, principalmente os ligados à produção de soja", se- 
gundo Sanae Hayashi, pesquisadora do Imazon. (Portalexame.abril.com.br)

Jornais - O Brasil conta com 465 jornais diários em junho de 2000, conforme a Associação Nacional de Jornais (ANJ). (Portalbrasil.net)

Devemos, porém, levar em consideração que a maioria (78\%) desses constituintes mantém a posição inicial. Dada a característica de uma informação nova, o falante vê-se na necessidade de qualificar a entidade, a fim de buscar no mundo a autoridade que dela emana, para conferir credibilidade ao seu texto, funcionando inclusive como valor argumentativo na validação da proposição.

Segundo o petista, Marina iria ouvir pessoas mais próximas a ela antes do encontro. (Folha.com)

De acordo com $O$ The National, ainda, Mustafa Alani, especialista em segurança do Centro de Pesquisas do Golfo em Dubai, que enfatizou que os Emirados Árabes Unidos poderiam usar a aeronave de transporte brasileira para expandir seu leque de missões humanitárias. (Oestadao.com)

Para a petista, o episódio da denúncia contra a ministra - que disse ter encontrado rapidamente em duas cerimônias após sair do governo somam-se ao escândalo da quebra de sigilos fiscais de tucanos como um conjunto de acusações para tentar desestabilizar sua candidatura. "Eles (os adversários) estão procurando a bala de prata, em busca da bala de prata. Sinto informar que não terão." (Portaldopurus.com.br)

Também observamos, em menor quantidade (9\%), satélites em posição intercalada. Como afirma Pezatti (2005, p. 71)

A alteração na ordenação linear desse constituinte está relacionada a determinação de ordem pragmática, como estatuto informacional (dado/ novo) e função pragmática (Tópico retomado).

Já observamos em exemplos anteriores que na posição inicial há ocorrência dos três constituintes. "De acordo com" e "segundo" ocorrem também na posição final. Este também foi o constituinte com maior ocorrência no meio das orações, porém não o único, pois observamos o "de acordo com" nesta posição.

Assim, podemos concluir que "segundo" e "de acordo com" podem ocorrer em todas as posições, porém o predomínio de ambos está na posição inicial. 
O Brasil, conforme a World Press Trends, é o país em que mais jornais lançam sites na rede, com um crescimento de $14 \%$ ao ano. (Portalbrasil.net)

Erenice diz em nota que irá à Justiça contra acusações. A ministrachefe da Casa Civil, Erenice Guerra, divulgou nota ontem (11) em que nega as denúncias publicadas na revista Veja. Israel Guerra, filho de Erenice e, segundo a reportagem, receberia dinheiro para intermediar contratos milionários entre empresários e órgãos do governo. (Portaldopurus.com.br)

Em relação à posição dos satélites fonte, concordamos com Pezatti ao apontar que, em português escrito, o constituinte "segundo" parece ser o preferido entre os brasileiros. $O$ índice de utilização e a sua mobilidade foram marcantes em nossa análise, dos 31 casos observados $78 \%$ são direcionadas para este uso. (Cf. Fig. 3)

As entidades humanas têm preferência neste tipo de satélite fonte, pelo menos nos textos que compreendem nosso corpus.

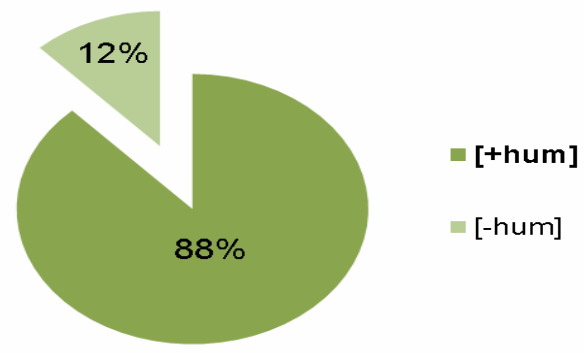

Figura 4. Resultado percentual de posicionamento dos satélites fonte.

Observe a figura 4 . Em $88 \%$ dos casos, na sua maioria representado pelo uso do "para", as entidades possuem traços humanos [+hum], fato explicável uma vez que se inserem na oração vozes com a finalidade de dar credibilidade à proposição.

Para Alani, o interesse árabe no Super Tucano brasileiro, um avião de combate leve, que poderia ser ideal para operações de contrainsurgência, segurança de fronteiras e combate ao tráfico de drogas. (Oestadao.com)

Para uma neófita no mundo da política como Dilma Rousseff, chegar à frente dos adversários no primeiro turno seria motivo de comemoração. Mas para quem chegou a ter chances de vitória já na 
primeira fase da eleição, o segundo turno tem gosto de derrota e de apreensão. (Portaldopurus.com.br)

Se falamos de vozes dentro da proposição, então evidenciamos na análise o fenômeno da polifonia, da citação no uso desses constituintes. Esta heterogeneidade do discurso, segundo Ducrot, é constitutiva do sujeito (ou locutor) que está em relação constante com um outro do discurso. Tal sujeito faz referência a este outro expressando sua ótica, dentro de uma enunciação, que pode ou não ser compatível com a sua (do sujeito). O outro expresso no discurso estaria se referindo a uma perspectiva ou postura de um ou mais enunciadores, segundo nomenclatura adotada por ele. Sendo assim, a distinção que se faz entre locutor e enunciador é de origem pragmática e semântica.

Podemos observar também a presença de entidades não humanas [-hum]. São poucas as ocorrências essencialmente não humanas, pois muitas das que classificamos (12\%) remetem metonimicamente a entidades [+hum], como no caso de Jornais, Institutos, Jornal, Órgãos Internacionais, Revista, e outros.

De acordo com $O$ The National, ainda, Mustafa Alani, especialista em segurança do Centro de Pesquisas do Golfo em Dubai, que enfatizou que os Emirados Árabes Unidos poderiam usar a aeronave de transporte brasileira para expandir seu leque de missões humanitárias. (Oestadao.com)

De acordo com a Chancelaria britânica, os "ataques poderiam ser indiscriminados, incluindo locais frequentados por residentes e turistas estrangeiros". Já o comunicado americano, que não especifica nenhum país europeu, informa que atentados poderiam ter como alvo "o sistema de transporte público e outras infraestruturas turísticas". (Oestadao.com)

O "de acordo com" tem preferência em nosso corpus como satélite Fonte que introduz uma entidade não humana, mas que, como já dissemos, metonimicamente remete a entidades [+hum]. A referenciação desses constituintes se apresenta tanto em termos definidos como indefinidos. Segundo Pezatti (2005, p. 74)

Termos definidos são usados para estabelecer referência identificadora, e indefinidos, para estabelecer referência construtora. Assim, por meio de termos definidos, $\mathrm{F}$ convida $\mathrm{D}$ a identificar um referente que ele supõe estar disponível para D; já por meio de termos indefinidos, F convida $\mathrm{D}$ a construir um referente conforme as propriedades especificadas. 
Observa-se que a maior parte dos constituintes são definidos porque o falante acredita, pragmaticamente, que seu interlocutor poderá identificar o referente por ele inserido Esta informação já seria do conhecimento deste interlocutor. Mesmo os indefinidos tornam-se identificáveis em alguma parte do texto.

De acordo cm Ciro Botelho, o palhaço Tiririca conta com a ajuda da mulher para decorar suas falas: "A mulher fica no camarim com ele e vai falando o texto. Ele vai decorando e conta do jeito dele" (Revistaepoca.globo.com)

Segundo o dirigente petista, o PT vai procurar abordar neste segundo turno a bandeira do desenvolvimento sustentável. Dutra disse que a questão é compatível com o partido. (Folha.com)

Em julho passado, segundo dados do Sistema de Alerta de Desmatamento (SAD), o estado paraense também foi o que mais desmatou. No período, a Amazônia perdeu $155 \mathrm{~km}^{2}$ de vegetação, sendo o Pará responsável por $51 \%$ (79 quilômetros quadrados). (Portalexame.abril.com.br)

Encontramos apenas dois casos que apresentaram indefinição nos termos apresentados: um iniciado pela preposição "segundo" e outro com a locução "de acordo com". Uma vez que os satélites fonte têm a função dar credibilidade a um texto, acreditamos que a utilização de constituintes definidos se justifica, pois a validação da proposição está na certeza de se assegurar que o interlocutor poderá identificar esse referente, por isso a definição ser amplamente utilizada nos textos analisados.

No novo figurino, segundo a reportagem, Israel operou, pelo menos, a concessão de um contrato de $\mathrm{R} \$ 84$ milhões para um empresário do setor aéreo com negócios com os Correios. Chamada de "taxa de sucesso", a propina foi estimada em R \$ 5 milhões e teria servido em parte para "saldar compromissos políticos". (Portaldopurus.com.br)

De acordo com a nota, o PV fará uma convenção nacional para decidir a questão. Na tarde desta terça-feira, Dutra havia afirmado que Marina Silva já tinha aceitado se reunir com a campanha de Dilma Rousseff para discutir o apoio. (Folha.com)

\section{A discursividade}

Observamos até o momento que a utilização dos satélites fonte tem por finalidade inserir uma origem/fonte que assegure a valida- 
ção, a verdade da proposição. Essa inserção, por meio de fenômenos como a polifonia ou a citação, atesta a heterogeneidade do discurso. Para Bakhtin, a citação é o modo mais evidente de se representar o discurso do outro, embora haja inúmeras formas de manifestação do jogo polifônico. O que podemos depreender na análise, é que o propósito comunicativo do falante revela um comprometimento ou então descomprometimento com a verdade.

O principal motivo desse crescimento são os investimentos das empresas em tecnologia - estima-se que entre 1995 e 2000 tenham sido gastos 600 milhões de dólares apenas em rotativas. Nesse período, novos parques gráficos são instalados e impressoras 4 x 4 compradas, o que aumenta a quantidade de jornais em cores e melhora a qualidade da impressão. Outro fator é a pronta adaptação dos jornais à internet. Segundo a World Press Trends, nosso país é que mais jornais lançam sites na rede, com um crescimento de $14 \%$ ao ano. (Portalbrasil.net)

No exemplo acima, observa-se o comprometimento do falante em relação à proposição. Justifica-se pelo fato de o texto reunir informações sobre o Brasil, informando que o país está crescendo e tem infraestrutura invejável no cenário mundial. $\mathrm{O}$ falante, então, compromete- se com o enunciado, toma esta voz como própria, objetivando a persuasão do leitor/interlocutor. Há uma aproximação entre o locutor e a World Press Trends, observada pela utilização do pronome possessivo "nosso". O falante, então, aproxima- se da voz do outro, a fim de garantir a validade da proposição, na intenção de persuadir seu interlocutor com a autoridade inserida na oração.

Outras vezes, entretanto, o falante tenta se distanciar do que é dito, vejamos:

Weslian foi indicada pelo marido, Joaquim Roriz (PSC), na última sexta-feira (24), após ele abrir mão da candidatura com receio de ser enquadrado na Lei da Ficha Limpa. Para Góes, a aceitação da candidatura de Weslian teria um efeito cascata, "legitimando diversas candidaturas laranja" em todo o país. Roriz é autor do recurso encaminhado ao Supremo Tribunal Federal (STF) que contesta a validade das novas regras eleitorais para este ano. (Oglobo.com)

No exemplo acima, o falante se distancia da voz apresentada, a responsabilidade do que é dito fica a cargo do outro na proposição inserida, há um distanciamento da verdade posta. Esse mecanismo é muito utilizado em textos midiáticos. Está presente na maior parte de nosso corpus, que tem por objetivo apresentar uma notícia sem se 
comprometer, atribuindo ao outro a responsabilidade pelo enunciado. Observe que o verbo, no futuro do pretérito, colabora para que o falante se exima da responsabilidade da fala.

Ainda sobre a discursividade, notamos que o propósito comunicativo é que indicará a melhor utilização dos satélites; o melhor constituinte a ser empregado. Em textos argumentativos como o que defende o Brasil (Brasil, economia e comunicações), ou o que critica a candidatura do palhaço Tiririca (Tiririca, o palhaço que não lê) analisados neste artigo, observa-se que a voz do outro é utilizada como argumento para as proposições inseridas no texto. $\mathrm{O}$ falante compromete-se com o que é dito, assume a voz, alicerçado na autoridade que este outro possui, como própria, como argumento para a tese que apresenta.

Já nos textos da Folha.com, Oglobo.com, Exame.com e Estadão.com, que se apresentam como reportagens, a tendência é contrária. Há um distanciamento entre o falante e os discursos inseridos pelos satélites fonte. A imparcialidade almejada, mesmo que no ponto de vista linguístico isso seja improvável, está inserida nesse gênero, a funcionalidade discursiva dessas notícias, o propósito enunciativo determinam, portanto, a utilização desses satélites como meio de validar uma proposição, neste caso, de forma objetiva sem comprometer o falante.

\section{Conclusão}

Apresentamos neste trabalho uma análise sobre os satélites fonte, baseados no texto de Pezatti (2005), que tem como pressuposto a teoria da gramática funcional de Dik. Observamos na análise que os constituintes "segundo", "de acordo com" e "para", nesta ordem, foram os de maior ocorrência em nosso corpus. A posição preferida foi a inicial, embora a utilização de satélites fonte ocorram também no meio e no final da oração.

O falante também tem preferência por definir a fonte, e mesmo as indefinições podem ser retomadas em alguma parte do texto; isso deve-se ao fato de o argumento servir como validação de uma proposição e, por isso, o interlocutor deve reconhecer a fonte como autoridade para que seja garantida esta validação. 
Com a utilização dos satélites fonte, o faltante pode ou não se comprometer com o que diz. Essa relação se dará de acordo com o propósito discursivo a que se destina o enunciado, pois os resultados obtidos mostram que ao inserir outra voz no discurso o falante expressa maior ou menor comprometimento com a verdade do enunciado, o propósito discursivo define essa relação.

Também podemos observar que as entidades selecionadas possuem, em sua grande maioria traços humanos e, mesmo aquelas com traços não humanos relacionam-se metonimicamente com representantes humanos, caso de jornais, partidos políticos, empresas, institutos internacionais e outros. Aqueles exclusivamente não humanos (somente dois), foram selecionados com os constituintes "segundo" e "de acordo com", portanto não podemos dizer qual a preferência neste trabalho, embora acreditamos ser possível observar isso em outro trabalho.

Observamos que a utilização dos satélites fonte evidencia a heterogeneidade polifônica do discurso, o que não nos permite restringir a análise somente no nível da oração. A informação como um todo é apresentada de forma empacotada, intencional, o que evidencia o proposito discursivo e norteia as estratégias do discurso. Esse jogo estratégico da linguagem é sempre um cálculo pragmático.

\section{REFERÊNCIAS BIBLIOGRÁFICAS}

BAKHTIN, Mikhail/ VOLOCHINOV, V. N. Marxismo e filosofia da linguagem. São Paulo: Hucitec, 2004.

BARBOSA, Vanessa. Portal Exame. Pará lidera desmatamento na Amazônia. Disponível em: http://portalexame.abril.com.br/meioambiente-e-energia/noticias/lider-desmatamento-amazonia601295.html. Acesso em: 28 set. 2010.

BRASIL e Emirados Árabes vão assinar 'amplo acordo de defesa'. Oestadao.com. 2010. Disponível em: http://www.estadao.com.br/noticias/nacional,brasil-e-emiradosarabes-vao-assinar-amplo-acordo-de-defesa,614839,0.htm. Acesso em: 24 set. 2010. 
DIK, S. C. The theory of functional grammar. Part 1: The Structure of the Clause. Dordrecht - Holland / Providence RI-USA: Foris Publications, 1989.

DUCROT, Dizer e não dizer. Princípios de semântica linguística. Trad. de Eduardo Guimarães. Campinas: Pontes, 1987.

ECONOMIA e comunicações. 2010. Disponível em:

www.portalbrasil.net/brasil_economia.htm. Acesso em: 28 set. 2010.

FERREIRA, Victor. Revistaepoca.globo.com. Tiririca, o candidato que não lê. Disponível em:

http://revistaepoca.globo.com/Revista/Epoca/0,EMI174615-

15223,00.html. Acesso em 24/09/2010.

GUIMARÃES, Eduardo. Texto e argumentação. 3. ed. Campinas: Pontes, 1987.

KOCH, Ingedore G. Villaça. Argumentação e linguagem. 11. ed. São Paulo: Cortez, 2008.

$\mathrm{KOCH}$, Ingedore G. Villaça. A inter-ação pela linguagem. 10. ed. São Paulo: Contexto, 2007.

MARINA desmente PT e nega que aceitou conversa sobre apoio a Dilma. folha.com. 2010. Disponível em:

http://www1.folha.uol.com.br/poder/810389-marina-desmente-pt-enega-que-aceitou-conversa-sobre-apoio-a-dilma.shtml. Acesso em: 04 out. 2010.

NOBLAT, Ricardo. Portal oglobo.com. Disponível em: http://oglobo.globo.com/pais/noblat/default.asp?a=111\&cod_blog=1 $29 \& \mathrm{ch}=\mathrm{n} \&$ palavra $=\&$ pagAtual $=4 \&$ periodo $=201009$. Acesso em: 29 set. 2010.

PEZATTI, Erotilde Goreti. A voz do outro, de uma perspectiva funcionalista. ALFA. São Paulo, n. 49, 2005: 65-86.

REPORTAGEM da revista Veja complica Dilma Rousseff. 2010. Disponível em: http://acritica.uol.com.br/noticias/dilma-vejaerenice-escandalo-denuncia-revista 0 333566695.html. Acesso em: 28 set. 2010.

VAN DIJK, T. A. Cognição, discurso e interação. São Paulo: Contexto, 2010. 